\title{
Institutional outbreak involving multiple clades of IMP-producing Enterobacter cloacae complex sequence type 78 at a cancer center in Tokyo, Japan
}

Sohei Harada ${ }^{1,2^{*}}$ D, Kotaro Aoki ${ }^{3}$, Daisuke Ohkushi ${ }^{2}$, Koh Okamoto ${ }^{4}$, Kazumi Takehana ${ }^{5}$, Tomomi Akatsuchi', Keito Ida ${ }^{6}$, Daigo Shoji ${ }^{6,7}$, Yoshikazu Ishii ${ }^{3}$, Yohei Doi ${ }^{8,9}$, Kyoji Moriya $^{1,4}$ and Brian Hayama ${ }^{2,6}$

\begin{abstract}
Background: Information about the clinical and microbiological characteristics of IMP-producing Enterobacterales has been limited. Here, we describe an institutional outbreak of IMP-producing Enterobacter cloacae complex (ECC) involving multiple clades of ECC sequence type (ST) 78 strains.

Methods: Antimicrobial susceptibility testing, whole-genome sequencing, and conjugation experiments of 18 IMPproducing ECC strains isolated during four-year study period were performed. Species and subspecies were determined by average nucleotide identity analysis and clonal relatedness of the isolates was analyzed with multilocus sequence typing and core-genome single nucleotide polymorphism (SNP) analysis. Relevant clinical information was extracted from medical records.

Results: Fourteen of 18 IMP-producing ECC isolates were determined as Enterobacter hormaechei ST78. Sixteen isolates, including 13 isolates belonging to ST78, carried bla IMP-1 in In316-like class 1 integron and also carried IncHI2

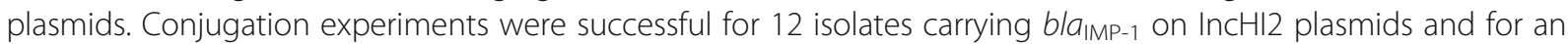
isolate carrying bla $a_{1 \mathrm{MP}-11}$ on an IncL/M plasmid. Although isolation of ST78 strains was clustered in a 14-months period suggesting nosocomial transmission, these strains were subdivided into three clades by SNP analysis: clade A $(n=10)$, clade $\mathrm{B}(n=1)$, clade $\mathrm{C}(n=3)$. A part of clonal relatedness was unexpected by the epidemiological information at the time of isolation of the strains. Most of the IMP-producing ECC strains were susceptible to non$\beta$-lactam antibiotics and had relatively low minimum inhibitory concentrations to carbapenems $(\leq 4 \mu \mathrm{g} / \mathrm{mL})$. Five of six infections caused by IMP-producing ECC were treated successfully.

(Continued on next page)
\end{abstract}

\footnotetext{
* Correspondence: haradas-tky@umin.ac.jp

'Department of Infection Control and Prevention, The University of Tokyo

Hospital, 7-3-1 Hongo, Bunkyo-ku, Tokyo 113-8655, Japan

${ }^{2}$ Department of Infectious Diseases, Cancer Institute Hospital, Japanese

Foundation for Cancer Research, 3-8-31 Ariake, Koto-ku, Tokyo 135-8550,

Japan

Full list of author information is available at the end of the article
}

(c) The Author(s). 2021 Open Access This article is licensed under a Creative Commons Attribution 4.0 International License, which permits use, sharing, adaptation, distribution and reproduction in any medium or format, as long as you give appropriate credit to the original author(s) and the source, provide a link to the Creative Commons licence, and indicate if changes were made. The images or other third party material in this article are included in the article's Creative Commons licence, unless indicated otherwise in a credit line to the material. If material is not included in the article's Creative Commons licence and your intended use is not permitted by statutory regulation or exceeds the permitted use, you will need to obtain permission directly from the copyright holder. To view a copy of this licence, visit http://creativecommons.org/licenses/by/4.0/ The Creative Commons Public Domain Dedication waiver (http://creativecommons.org/publicdomain/zero/1.0/) applies to the data made available in this article, unless otherwise stated in a credit line to the data. 
(Continued from previous page)

Conclusions: Whole-genome sequencing analysis revealed the outbreak was caused by three different clades of ST78 strains, where patients had favorable treatment outcome of the infections compared with that caused by Enterobacterales producing other carbapenemases, possibly due to their non-multidrug-resistant phenotype.

Keywords: Enterobacter cloacae complex, IMP-type carbapenemase, Outbreak, Whole-genome sequencing, Single nucleotide polymorphism analysis

\section{Background}

Carbapenem-resistant Enterobacterales (CRE) has been spreading globally during the last decade and acknowledged as an imminent risk for public health due to the limited treatment options for the infections caused by the organisms [1]. Among the various mechanisms of carbapenem resistance in Enterobacterales, production of carbapenemases is clinically the most important. Carbapenemase-producing Enterobacterales (CPE) may have a higher risk of detrimental outcomes from invasive infections and of spreading resistance genes in healthcare facilities by clonal expansion or conjugative transfer of resistance plasmids compared with non-carbapenemaseproducing CRE $[2,3]$. KPC enzymes belonging to Ambler class A, IMP, VIM, NDM enzymes (metallo- $\beta$-lactamases: MBLs) belonging to Ambler class $\mathrm{B}$, and OXA-48-group enzymes belonging to Ambler class $\mathrm{D}$ are the major carbapenemases produced by Enterobacterales. Although KPC enzymes are the most common globally, epidemiology of carbapenemases produced by Enterobacterales differs in each region and country of the world [4].

Carbapenem resistance among Enterobacterales clinical strains has been relatively infrequent in Japan. A national surveillance conducted by National Institute of Infectious Diseases reported that resistance rates to meropenem of Escherichia coli, Klebsiella pneumoniae, and Enterobacter cloacae complex (ECC) in 2018 were 0.1 , 0.5 , and $1.1 \%$, respectively (https://janis.mhlw.go.jp/ english/report/open_report/2018/3/1/ken_Open_ Report_Eng_201800_clsi2012.pdf). Although IMP enzymes have been overwhelmingly dominant among carbapenemases produced by Enterobacterales in Japan, major species of CPE is different in each geographic area in Japan. While IMP-producing ECC is most common in Tokyo, IMP-producing K. pneumoniae and E. coli are more common around Osaka $[5,6]$.

While transmission dynamics of KPC-producing Enterobacterales in healthcare facilities have been reported abundantly in the literature, information about transmission of IMP-producing Enterobacterales is scarce [7-9]. Although a recent study demonstrated that mortality of patients with isolation of IMP-producing Enterobacterales was similar to that of patients with isolation of non-CPE, detailed characteristics of infections caused by IMP-producing Enterobacterales remain to be clarified [10]. Although recent global clinical studies have addressed treatment of infections caused by CPE, few cases of infections caused by IMP-producing Enterobacterales were included due to their rarity [11].

Starting in July 2014, an outbreak of IMP-producing ECC occurred at a cancer center in Tokyo, Japan. Here, we report the clinical characteristics of infections caused by IMP-producing Enterobacterales and the results of microbiological and molecular analysis to infer the route of transmission.

\section{Methods \\ Setting and design}

This is a descriptive study of an institutional outbreak of CPE at a 700-bed cancer center in Tokyo, Japan. It provides care for patients with all type of malignancies. Annually, 17,500 patients are hospitalized with a mean of 12 days. All the CPE isolates between January 2014 and December 2017 were analyzed. In addition, clinical and epidemiological investigation was performed for all the patients who had CPE isolated.

\section{Clinical data collection}

Clinical information of the patients with CPE was extracted from the medical records retrospectively and included age, sex, type of malignancy and other comorbidities, date of the first isolation of CPE, type of sample from which CPE was isolated, hospitalized ward, department caring the patient, clinical significance of the CPE isolates (infection or colonization), use of antimicrobial agents within 30 days prior to the isolation of CPE, type and date of surgery within 90 days prior to the isolation, type of endoscopy within 90 days prior to the isolation, cancer chemotherapy within 90 days prior to the isolation, admission to the hospital during the study period and to other hospitals within a year prior to the isolation, and death within 30 and 90 days after the isolation of CPE. Additionally, the type of infection, antimicrobial treatment, necessity and achievement of source control, and prognosis were reviewed for the cases with infections caused by CPE. Infection and colonization were determined according to the CDC definition [12]. 


\section{Identification of carbapenemase-producing Enterobacterales at the hospital}

Routine bacterial identification and antimicrobial susceptibility testing were performed with MicroScan WalkAway (Beckman Coulter, Brea, CA, USA) at the hospital. The results of antimicrobial susceptibility testing were interpreted with CLSI M100-S17 guidelines in 2014, and with CLSI M100-S22 guidelines, in which lower breakpoints of cephalosporins and carbapenems for Enterobacterales were adopted, from 2015 through 2017 $[13,14]$. Testing for carbapenemase production was performed on the isolates showing non-susceptibility against cefepime or any carbapenems. Non-susceptibility to cefepime was added to the screening criteria due to concerns about low sensitivity of the screening using non-susceptibility to carbapenems alone for the detection of IMP-producing Enterobacterales [15]. Carbapenemase production (focusing on MBLs) was confirmed with ceftazidime 30- $\mu \mathrm{g}$ disks (Eiken Chemical, Tokyo, Japan), imipenem 10- $\mu$ g disks (Eiken Chemical, Tokyo, Japan), and sodium mercaptoacetate (SMA) 3-mg disks (Eiken Chemical, Tokyo, Japan). Isolates showing enlargement of inhibitory zone diameters around the ceftazidime disk or imipenem disk by $>5 \mathrm{~mm}$ when it was located adjacent to an SMA disk were determined to be carbapenemase-producing Enterobacterales [16, 17]. Additionally, modified carbapenem inactivation method (mCIM) according to CLSI M100-S27 guidelines was performed after April 2017 [18].

\section{Active surveillance culture for CPE}

A ward-wide active surveillance for multidrug-resistant Enterobacterales was conducted for the selected wards intermittently during the study period. All patients except those hospitalized less than 3 days were included. Stool or rectal swab samples were obtained. If patients had urinary catheters placed, urine was collected. Because epidemiological investigation suggested possible transmission associated with respiratory procedures among post-surgical patients in Surgery-B department, throat swab was also collected from those patients. Culture was performed using CHROMagar ESBL (Kanto Chemical, Tokyo, Japan). Antimicrobial susceptibility testing was performed on the isolates grown on the agar and CPE was identified with the same protocol as clinical culture.

\section{Microbiological and molecular analysis}

All CPE isolates detected first from each patient at the hospital were collected and analyzed at a research laboratory. Because susceptibility testing of carbapenems with drug concentration below $4 \mu \mathrm{g} / \mathrm{mL}$ was not performed at the hospital in 2014, antimicrobial susceptibility testing of all isolates was conducted again at the research laboratory with BD Phoenix NMIC/ID-208 panel (BD Diagnostics, Sparks, Maryland, USA) and results were interpreted according to CLSI M100-S27 guidelines [18]. Carriage of bla $a_{\mathrm{IMP}-1 \text {-group genes was }}$ screened by PCR as described previously [19]. Whole genome sequencing was performed with Illumina Miseq (Illumina, San Diego, California, USA). Genomic DNA libraries were prepared with Nextera XT DNA library preparation kit (Illumina) and were sequenced for 600 cycles (300-bp paired-end reads). Raw reads generated by Miseq were quality trimmed with Trimmomatic tool (version 0.38) and assembled using SPAdes (version 3.12.0). Since all CPE isolates were identified as ECC or related species by MicroScan WalkAway at the hospital, species and subspecies were determined by comparing the average nucleotide identity (ANI) of the genomes of study isolates with those of type strains of ECC using a threshold of $>96.5 \%$ at ANI Calculator of EZ BioCloud website (https://www.ezbiocloud.net/tools/ani) [20]. Multilocus sequence typing (MLST), plasmid replicon typing, plasmid MLST, and screening of acquired resistance genes were conducted with MLST 1.8, PlasmidFinder 1.3, pMLST 1.4, and ResFinder 3.0, respectively, at Centers for Genomic Epidemiology website (https://cge.cbs.dtu.dk/ services/). Structures of integrons were analyzed with Basic Local Alignment Search Tool (BLAST) (https:// blast.ncbi.nlm.nih.gov/Blast.cgi) using nucleotide sequences of contigs containing bla $a_{\mathrm{IMP}-1 \text {-group. Core-genome }}$ single nucleotide polymorphism (SNP)-based phylogenetic analysis of ST78 isolates of ECC was performed as described previously using genomic sequence of $E$. cloacae strain 109 belonging to ST78 (GenBank accession number NZ_CP020525) as the reference [6]. Conjugation experiments were carried out with filter mating methods using non-lactose-fermenting E. coli ML4909 strain (a rifampinresistant mutant derived from $E$. coli $\mathrm{K}-12$ ) as a recipient. Transconjugants were selected on Drigalski lactose agar supplied with moxalactam $(16 \mu \mathrm{g} / \mathrm{mL})$ and rifampin $(100 \mu \mathrm{g} / \mathrm{ml})$. The conjugation experiment was attempted three times for each donor isolate. Carriage of $b l a_{\text {IMP-1-group }}$ were confirmed with PCR and PCR-based replicon typing of the plasmids were performed for transconjugants [21].

\section{GenBank accession number}

All nucleotide sequences of draft genomes have been deposited in the NCBI database under BioProject accession number PRJDB9939.

\section{Results}

\section{Outbreak description}

In July 2014, CPE was detected from a hospitalized patient at the cancer center for the very first time. In total, 18 hospitalized patients were found to have CPE during 
the study period confirmed by clinical culture $(n=13)$ or surveillance culture $(n=5)$ (Table 1, Table S1). Seventeen and one isolates were identified as E. claocae and Cronobacter sakazakii, respectively, with MicroScan WalkAway. All isolates were positive for production of MBLs by the SMA disk testing. Date of first isolation of CPE from all but one (Patient-18) patients was clustered in a 16-months period (between July 2014 and Oct 2015). The mean age of 18 patients was 68.8 years. Sixteen patients $(88.9 \%)$ were male. Seventeen patients (94.4\%) had gastrointestinal malignancy. Six (33.3\%), fourteen $(77.8 \%)$, and sixteen $(88.9 \%)$ patients had received chemotherapy within 90 days, surgery within 90 days, and antimicrobial therapy within 30 days of the first isolation of CPE, respectively. Although the patients were under the care of 7 different departments, SurgeryA $(n=7)$, Surgery-B $(n=4)$, and Medical Oncology-E $(n=3)$ departments were involved in the care of multiple patients. At the time of CPE isolation, the patients were located at one of five different wards or one intensive care unit (ICU). Six, five, and three patients were at ICU, Ward-V, and Ward-X, respectively. Fifteen patients (83.3\%) received endoscopic procedure within 90 days of isolation of CPE. All six patients from whom CPE was isolated within 3 days after surgery (Patient-2, $-5,-10$, $-14,-15$, and -16$)$ received routine airway nebulization and frequent airway suctioning at ICU and bronchoscopy was also performed at operating rooms in two patients (Patient 5 and -15). Thirteen (76\%) of seventeen case patients between July 2014 and Oct 2015 had history of hospitalization at multiple wards before the isolation of CPE (Fig. 1).

A ward-wide active surveillance was performed twice at Ward-V (November 2014 and February 2015), three times at Ward-X (May, June, and July 2015), and once at Ward Y (November 2014). A total of 191 patients were screened and two patients were positive for carriage of $\mathrm{CPE}(\mathrm{Pa}-$ tient-7 and -12). Additionally, a patient with a history of admission in Ward-V was screened upon a later admission at Ward-X and was positive for the growth of CPE (Patient-9). Surveillance cultures performed at the discretion of primary physicians immediately after surgery without using selective media turned positive for carriage of $\mathrm{CPE}$ in two patients (Patient-2 and -6).

Six patients had infections due to CPE (Table 2). Although one patient died of an intraabdominal infection following intestinal perforation on the 11th day of the onset of the infection, infections in other patients were cured without relapse. Two other patients died within 90 days due to reasons unrelated to the carriage of CPE (Table S1).

\section{Outbreak management}

The patients with a history of isolation of CPE were cared for in a private room under contact precautions according to the infection prevention protocol of the hospital. After July 2014 when the isolation of CPE from patients hospitalized in different wards was documented, occurrence of an institutional outbreak of CPE was notified to the all hospital staffs and strict compliance to the infection prevention protocol was enforced. In addition, direct observation of hand hygiene compliance was initiated by infection preventionists and the data were fed back to each hospital department. Compliance to the infection prevention protocol was thoroughly checked especially at the wards where the patients with CPE was hospitalized. Sampling from hospital environment was not performed. Compliance to the cleaning and disinfection protocol of endoscopes was confirmed and bacterial cultures of the relevant endoscopes, including bronchoscopes for the operating rooms and ICU and duodenoscope, were negative for the growth of CPE.

\section{Microbiological and molecular analysis of CPE}

All CPE isolates were non-susceptible to cefepime and all but one isolates were non-susceptible to piperacillintazobactam with BD Phoenix NMIC/ID-208 panel. Three isolates were susceptible to aztreonam. Although most of the isolates were non-susceptible to carbapenems, MIC of $>4 \mu \mathrm{g} / \mathrm{mL}$ for imipenem and meropenem was observed only in two isolates and one isolate, respectively. Most of the isolates was susceptible to non- $\beta$ lactam antibiotics tested (Table 3).

Fourteen of eighteen CPE isolates were identified as $E$. hormaechei by ANI and other isolates were $E$. hormaechei subsp. steigerwaltii $(n=2)$, E. asburiae $(n=1)$, and E. xiangfangensis $(n=1)$ (Table 3). All E. hormaechei isolates were ST78 and isolated between July 2014 and August 2015. While one isolate (TUM17942) carried $b l a_{\mathrm{IMP}-11}$, all other isolates carried $b l a_{\mathrm{IMP}-1}$. As expected, all isolates carried chromosomal $\operatorname{ampC}$ genes, but acquired genes for extended-spectrum $\beta$-lactamases (ESBL), AmpC, and carbapenemases other than $b l a_{\mathrm{IMP}}$ were not identified in any isolates. Plasmid replicon for IncHI2 was documented in 16 isolates and six of these (TUM14648, TUM14652, TUM17945, TUM17946, TUM17947, TUM17949) were pMLST-ST1 (smr0119:1smr0018:1). While remaining 10 isolates also had allele 1 of smr00119, smr00118 had 0.3\% difference from allele 1 in four isolates (TUM14647, TUM17939, TUM17943, TUM17944), were not fully sequenced in two isolates (TUM14654. TUM17940), and were non-typable in four isolates (TUM14658, TUM14792, TUM14797, TUM17948).

All isolates carrying $b l a_{\mathrm{IMP}-1}$ had In316 (intI1bla $a_{\mathrm{IMP}-1-a a c}\left(6^{\prime}\right)$-IIc-sul1)-like structure. In 7 isolates (TUM17941, TUM17943, TUM17945, TUM17946, TUM17947, TUM17948, and TUM17949), nucleotide sequences of In 316 were completely preserved and other 
Table 1 Clinical characteristics of patients from whom carbapenemase-producing Enterobacterales strains were isolated

\begin{tabular}{|c|c|c|c|}
\hline Characteristics & $\begin{array}{l}\text { All } \\
\text { patients } \\
(n=18)\end{array}$ & $\begin{array}{l}\text { Patients with } \\
\text { isolation of } \\
\text { ECC ST78 } \\
(n=14)\end{array}$ & $\begin{array}{l}\text { Patients with } \\
\text { isolation of } \\
\text { ECC non-ST78 } \\
(n=4)\end{array}$ \\
\hline Age, mean y [SD] & $\begin{array}{l}68.8 \\
{[8.1]}\end{array}$ & $69.1[7.7]$ & $67.8[9.0]$ \\
\hline Age $>65 y$ & $12(66.7)$ & $9(64.3)$ & $3(75)$ \\
\hline \multicolumn{4}{|l|}{ Sex } \\
\hline Male & $16(88.9)$ & $13(92.9)$ & $3(75)$ \\
\hline Female & $2(11.1)$ & $1(7.1)$ & $1(25)$ \\
\hline \multicolumn{4}{|l|}{ Status } \\
\hline Infection & $6(33.3)$ & $5(35.7)$ & $1(25)$ \\
\hline $\begin{array}{l}\text { Colonization detected by } \\
\text { clinical cultures }\end{array}$ & $7(38.9)$ & $4(28.6)$ & $3(75)$ \\
\hline $\begin{array}{l}\text { Colonization detected by } \\
\text { surveillance cultures }\end{array}$ & $5(27.8)$ & $5(35.7)$ & $0(0)$ \\
\hline \multicolumn{4}{|c|}{ Sample from which CPE was first isolated } \\
\hline Sputum & $6(33.3)$ & $5(35.7)$ & $1(25)$ \\
\hline Bile & $3(16.7)$ & $0(0)$ & $3(75)$ \\
\hline Stool & $3(16.7)$ & $3(21.4)$ & $0(0)$ \\
\hline Intraabdominal fluid & $2(11.1)$ & $2(14.3)$ & $0(0)$ \\
\hline Other & $4(22.2)$ & $4(28.6)$ & $0(0)$ \\
\hline
\end{tabular}

Ward at the time of isolation of CPE

$\begin{array}{llll}\text { ICU } & 6(33.3) & 4(28.6) & 2(50) \\ \text { Ward-V } & 5(27.8) & 5(35.7) & 0(0) \\ \text { Ward-X } & 3(16.7) & 3(21.4) & 0(0) \\ \text { Other } & 4(22.2) & 2(14.3) & 2(50)\end{array}$

Department at the time of isolation of CPE

$\begin{array}{llll}\text { Surgery-A } & 7(38.9) & 5(35.7) & 2(50) \\ \text { Surgery-B } & 4(22.2) & 4(28.6) & 0(0) \\ \text { Medical Oncology-E } & 3(16.7) & 3(21.4) & 0(0) \\ \text { Other } & 4(22.2) & 2(14.3) & 2(50)\end{array}$

Type of malignancy

$\begin{array}{llll}\text { Gastrointestinal } & 17(94.4) & 14(100) & 3(75) \\ \text { Thoracic } & 1(5.6) & 0(0) & 1(25) \\ \begin{array}{l}\text { Cancer chemotherapy within } \\ 90 \text { days }\end{array} & 6(33.3) & 6(42.9) & 0(0) \\ \begin{array}{l}\text { Antimicrobial use within } 30 \\ \text { days }\end{array} & 16(88.9) & 13(92.9) & 3(75) \\ \begin{array}{l}\text { Surgery within } 30 \text { days } \\ \text { Gastrointestinal }\end{array} & 14(77.8) & 10(71.4) & 4(100) \\ \text { Thoracic } & 13(72.2) & 10(71.4) & 3(75) \\ \begin{array}{l}\text { Endoscopic procedure within } \\ \text { 90 days }\end{array} & 15(5.6) & 0(0) & 1(25) \\ \quad \begin{array}{l}\text { Laryngoscopy } \\ \text { Esophagogastroscopy }\end{array} & 12(85.7) & 3(75) \\ \text { Duodenoscopy with ERCP } & 4(22.2) & 2(14.3) & 2(50)\end{array}$

Table 1 Clinical characteristics of patients from whom carbapenemase-producing Enterobacterales strains were isolated (Continued)

\begin{tabular}{clll}
\hline Characteristics & $\begin{array}{l}\text { All } \\
\text { patients } \\
(\boldsymbol{n}=\mathbf{1 8})\end{array}$ & $\begin{array}{l}\text { Patients with } \\
\text { isolation of } \\
\text { ECC ST78 } \\
(\boldsymbol{n}=\mathbf{1 4 )}\end{array}$ & $\begin{array}{l}\text { Patients with } \\
\text { isolation of } \\
\text { ECC non-ST78 } \\
(\boldsymbol{n}=\mathbf{4})\end{array}$ \\
\hline Colonoscopy & $6(33.3)$ & $5(35.7)$ & $1(25)$ \\
Bronchoscopy & $2(11.1)$ & $2(14.3)$ & $0(0)$ \\
30-day mortality & $1(5.6)$ & $1(7.1)$ & $0(0)$ \\
90-day mortality & $3(16.7)$ & $2(14.3)$ & $1(25)$ \\
\hline
\end{tabular}

Data are mean [SD] or $\mathrm{n}(\%)$

${ }^{a}$ If a patient received multiple endoscopic procedure, all were counted separately

ECC Enterobacter cloacae complex, CPE carbapenemase-producing

Enterobacterales, ERCP endoscopic retrograde cholangiopancreatography

isolates had single nucleotide difference $(n=5)$ or had fragmentation of the structure into multiple contigs $(n=5)$.

ST78 isolates were divided into three clades by coregenome $(4,257,370 \mathrm{bp}, 82.8 \%$ of the genomic sequence of the reference strain) based SNP analysis (Fig. 2). All patients from whom isolates of clade A were identified had a history of admission at ICU, Ward-V, or Ward-Y. On the other hand, all patients from whom isolates of clade $\mathrm{C}$ were identified had a history of multiple admission at Ward-X (Fig. 1).

\section{Conjugation experiments}

In 13 isolates, $b l a_{\mathrm{IMP}}$ was successfully transferred into recipient E. coli cell by conjugation experiment (Table 3). All transconjugant were positive for PCR using primers for $b_{\text {IMP-1-group. TUM17942 yielded transconjugants }}$ positive for IncL/M by PCR-based replicon typing. Transconjugants of the remaining isolates were positive for IncHI2 by PCR-based replicon typing, which suggested the location of $b l a_{\mathrm{IMP}-1}$ on IncHI2 plasmids.

\section{Discussion}

During the study period, carriage of CPE by 18 patients was identified. Molecular analysis of the isolates demonstrated an institutional outbreak of IMP-producing ECC ST78 which occurred in 14 patients over 14-months across multiple wards and departments. Core genomebased SNP analysis unexpectedly revealed that the outbreak involved three clades of ST78 isolates suggesting multiple introductions and routes of spread.

ST78 has been recognized as one of the global resistant clones of ECC [22]. ST78 isolates carrying bla $a_{\mathrm{KPC}}$, $b l a_{\mathrm{VIM}}$, and $b l a_{\mathrm{OXA}-48 \text {-group }}$ have been reported, together with the isolates with $b l a_{\mathrm{IMP}}[22-24]$. We previously reported that multiple clades of ST78 isolates carrying bla IMP-1 $_{\mathrm{I}}$ on IncHI2 plasmids had spread in Tokyo [6]. In this study, we found that multiple clades of ST78 were 


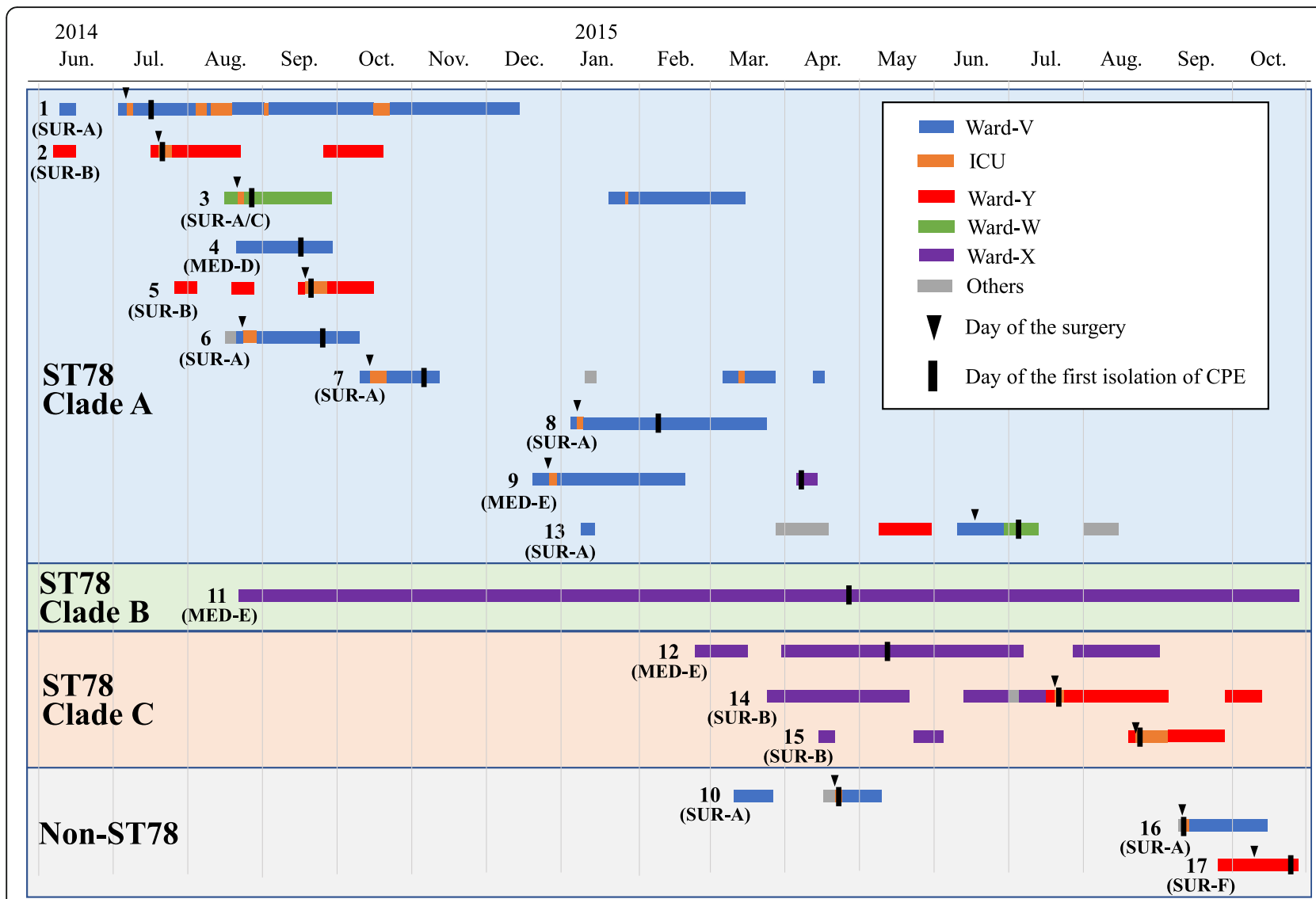

Fig. 1 Timeline of hospitalization, surgery, and first isolation of carbapenemase-producing Enterobacterales of the patients. The numbers located at the left end of the bars represent Patient ID. The departments caring the patients at the time of isolation of carbapenemase-producing Enterobacterales were presented below the Patient ID. SUR, Surgery; MED, Medical Oncology

indeed involved during 16-months outbreak within a single institution. Epidemiological investigation in combination with conventional microbiological analysis was insufficient to elucidate the details of the outbreak, and use of whole-genome sequencing-based analysis, with its resolution to differentiate similar clones, was crucial as described in other outbreaks [7-9].

Two ancestral isolates of clade A (isolates from Patient-1 and -2) had two SNPs differences but no common ancestor of these isolates was identified (Fig. 2). Nevertheless, the time of introduction of the original isolate of clade A was expected to be within a few months prior to the first identification of IMPproducing ECC at this hospital (July 2014), considering that average substitution rate of IMP-producing ST78 isolates in Tokyo was $4.53 \mathrm{SNPs} /$ genome/year in the previous study [6]. Clade A isolates were detected from 10 patients during one-year period, all of whom had a history of hospitalization at ICU, Ward-V, or Ward-Y (Fig. 1). We hypothesized that these isolates were transmitted through medical care either via medical device, environment, or healthcare workers during hospitalization in these wards. While Patient- 4 had history of hospitalization only at Ward-V, Patient-2, $-3,-5$ had no history of hospitalization at Ward-V prior to the isolation of clade A isolates. Therefore, involvement of multiple wards in the transmission of clade A isolates was suggested.

An isolate of clade B was isolated only from Patient-11 and carried $b a_{\mathrm{IMP}-11}$ on an IncL/M plasmid. IMP-11producing ECC isolates harboring IncL/M plasmids have been reported from Japan [10]. In addition, this patient had a history of recent long-term hospitalization at another hospital. Therefore, acquisition of the clade B isolate likely occurred outside the cancer center.

Clade $\mathrm{C}$ isolates were detected from three patients who had been all hospitalized in Ward-X during the same period. IMP-producing isolates were identified from the sputum of Patient-14 and -15 on the next day of the surgery performed by the same department (Surgery-B) at ICU, thus acquisition through respiratory procedure at ICU or bronchoscopy at operating rooms was suspected based on epidemiological information (Table S1). However, the whole-genome sequencing analysis 
Table 2 Clinical characteristics and outcomes of infections caused by carbapenemase-producing Enterobacterales strains

\begin{tabular}{|c|c|c|c|c|c|c|c|}
\hline $\begin{array}{l}\text { Patient } \\
\text { No. }\end{array}$ & $\begin{array}{l}\text { Diagnosis of } \\
\text { the infectious } \\
\text { diseases }\end{array}$ & Setting & $\begin{array}{l}\text { Samples } \\
\text { positive for } \\
\text { CPE }\end{array}$ & $\begin{array}{l}\text { Adequate source } \\
\text { control }\end{array}$ & $\begin{array}{l}\text { Antimicrobial } \\
\text { treatment }^{\mathrm{a}}\end{array}$ & Prognosis & Comment \\
\hline 1 & $\begin{array}{l}\text { Cholangitis Liver } \\
\text { abscess }\end{array}$ & $\begin{array}{l}\text { After resection of } \\
\text { gastrointestinal } \\
\text { malignancy and } \\
\text { choledochoduodenostomy }\end{array}$ & $\begin{array}{l}\text { Blood (Day 1, } \\
\text { Day 28) } \\
\text { Drained } \\
\text { abscess (Day } \\
\text { 29) }\end{array}$ & $\begin{array}{l}\text { Established } \\
\text { (percutaneous } \\
\text { abscess drainage) }\end{array}$ & $\begin{array}{l}\text { (Day 1-3) FEP } \\
\text { (IV) } \\
\text { (Day 3-8) } \\
\text { MEM (IV) + } \\
\text { GEN (IV) } \\
\text { (Day 9-28) } \\
\text { MEM (IV) } \\
\text { (Day 29-30) } \\
\text { MEM + GEN } \\
\text { (IV) + LVX (IV) } \\
\text { (Day 31-43) } \\
\text { MEM (HD-EX, } \\
\text { IV) + } \\
\text { GEN (IV) + LVX } \\
\text { (IV) } \\
\text { (Day 44-74) } \\
\text { TZP (HD-EX, } \\
\text { IV) + } \\
\text { GEN (IV) + LVX } \\
\text { (IV) }\end{array}$ & $\begin{array}{l}\text { Cure } \\
\text { without } \\
\text { 2nd } \\
\text { relapse }\end{array}$ & $\begin{array}{l}\text { Cholangitis with bacteremia due to CPE } \\
\text { developed } 9 \text { days after surgery was treated } \\
\text { with MEM (Day 3-28) according to the } \\
\text { susceptible result at the hospital. Although } \\
\text { fever and bacteremia were once resolved, } \\
\text { they recurred on Day } 28 \text {. C C scan of the } \\
\text { abdomen revealed liver abscess. } \\
\text { Percutaneous abscess drainage was } \\
\text { performed and antimicrobial treatment } \\
\text { was re-initiated. TZP (Day 44-74) was se- } \\
\text { lected according to the susceptible result } \\
\text { at the hospital. }\end{array}$ \\
\hline 3 & $\begin{array}{l}\text { Surgical site } \\
\text { infection (deep } \\
\text { incisional) }\end{array}$ & $\begin{array}{l}\text { After resection of } \\
\text { gastrointestinal } \\
\text { malignancy }\end{array}$ & Abscess (Day 1) & $\begin{array}{l}\text { Established } \\
\text { (incision and } \\
\text { drainage) }\end{array}$ & $\begin{array}{l}\text { (Day 1-9) TZP } \\
\text { (IV) } \\
\text { (Day 9-17) } \\
\text { MEM (IV) } \\
\text { (Day 17-25) } \\
\text { LVX (PO) }\end{array}$ & $\begin{array}{l}\text { Cure } \\
\text { without } \\
\text { relapse }\end{array}$ & $\begin{array}{l}\text { Deep incisional surgical site infection } \\
\text { developed } 5 \text { days after surgery. MEM (Day } \\
\text { 9-17) was selected according to the } \\
\text { susceptible result at the hospital. }\end{array}$ \\
\hline 4 & $\begin{array}{l}\text { Intraabdominal } \\
\text { infection }\end{array}$ & $\begin{array}{l}\text { Under palliative care for } \\
\text { advanced gastrointestinal } \\
\text { malignancy }\end{array}$ & $\begin{array}{l}\text { Intraabdominal } \\
\text { fluid (Day 1) }\end{array}$ & Unestablished & $\begin{array}{l}\text { (Day 1-6) } \\
\text { MEM (IV) } \\
\text { (Day 6-11) } \\
\text { IPM (IV) }\end{array}$ & $\begin{array}{l}\text { Death } \\
\text { (Day 11) }\end{array}$ & $\begin{array}{l}\text { Although intestinal perforation was } \\
\text { suspected by imaging studies, surgical } \\
\text { intervention was not performed because } \\
\text { the patient was on do-not-resuscitate } \\
\text { order due to his advanced cancer. IPM } \\
\text { (Day 6-11) was selected according to the } \\
\text { susceptible result at the hospital. }\end{array}$ \\
\hline 8 & $\begin{array}{l}\text { Intraabdominal } \\
\text { infection }\end{array}$ & $\begin{array}{l}\text { After resection of } \\
\text { gastrointestinal } \\
\text { malignancy }\end{array}$ & $\begin{array}{l}\text { Intraabdominal } \\
\text { fluid (Day 1) }\end{array}$ & $\begin{array}{l}\text { Established } \\
\text { (percutaneous } \\
\text { fluid drainage) }\end{array}$ & $\begin{array}{l}\text { (Day 1-7) } \\
\text { AMC (PO) }\end{array}$ & $\begin{array}{l}\text { Cure } \\
\text { without } \\
\text { relapse }\end{array}$ & $\begin{array}{l}\text { An intraabdominal fluid collection was } \\
\text { found on abdominal } \subset \text { scan } 34 \text { days after } \\
\text { surgery. Percutaneous fluid drainage was } \\
\text { performed and the culture of fluid grew } \\
\text { CPE. A low-grade fever subsided after the } \\
\text { percutaneous fluid drainage. }\end{array}$ \\
\hline 15 & Pneumonia & $\begin{array}{l}\text { After resection of } \\
\text { gastrointestinal } \\
\text { malignancy }\end{array}$ & Sputum (Day 1) & Unnecessary & $\begin{array}{l}\text { (Day 1-3) } \\
\text { SAM (IV) } \\
\text { (Day 3-14) } \\
\text { MEM (IV)+ } \\
\text { LVX (IV) }\end{array}$ & $\begin{array}{l}\text { Cure } \\
\text { without } \\
\text { relapse }\end{array}$ & $\begin{array}{l}\text { High fever and productive cough } \\
\text { developed on the next day of surgery, A } \\
\text { new pulmonary infiltrate was found on } \\
\text { chest X-ray. }\end{array}$ \\
\hline 16 & $\begin{array}{l}\text { Surgical site } \\
\text { infection (deep } \\
\text { incisional and } \\
\text { intraabdominal } \\
\text { space) }\end{array}$ & $\begin{array}{l}\text { After resection of } \\
\text { gastrointestinal } \\
\text { malignancy }\end{array}$ & $\begin{array}{l}\text { Blood (Day 1) } \\
\text { Abscess (Day 1) } \\
\text { Intraabdominal } \\
\text { fluid (Day 3) }\end{array}$ & $\begin{array}{l}\text { Established } \\
\text { (incision and } \\
\text { drainage of the } \\
\text { wound surface, } \\
\text { and percutaneous } \\
\text { peritoneal drainage) }\end{array}$ & $\begin{array}{l}\text { (Day 1-3) } \\
\text { MEM (IV) + } \\
\text { GM (IV) } \\
\text { (Day 3-21) } \\
\text { MEM (HD-EX, } \\
\text { IV) + GEN (IV) } \\
\text { (Day 22-24) } \\
\text { SXT (PO) } \\
\text { (Day 24-38) } \\
\text { LVX (PO) }\end{array}$ & $\begin{array}{l}\text { Cure } \\
\text { without } \\
\text { relapse }\end{array}$ & $\begin{array}{l}\text { CPE was first identified from surveillance } \\
\text { bile culture during the surgery prior to the } \\
\text { onset of infection. SXT was changed to } \\
\text { LVX (Day 24) due to the possible side } \\
\text { effect of nausea. }\end{array}$ \\
\hline
\end{tabular}

\footnotetext{
a Only antimicrobial agents with activity gram-negative organisms were presented. Antimicrobial agents against which the causative organisms were susceptible by antimicrobial susceptibility testing with BD Phoenix NMIC/ID-208 panel interpreted with CLSI M100-S27 guidelines were underlined FEP cefepime, MEM meropenem, GEN gentamicin, LVX levofloxacin, TZP piperacillin-tazobactam, IPM imipenem, AMC amoxicillin-clavulanic acid, SAM ampicillinsulbactam, SXT trimethoprim-sulfamethoxazole, HD-EX high-dose and extended infusion, $I V$ intravenous, PO oral
}

revealed that Patient-12 was the index patient and transmission to Patient-14 and 15 most likely occurred during the hospitalization at Ward-X several months prior to the surgery. Cancer patients often require multiple hospitalizations at different wards and are managed by different departments including surgery, radiology, and medical oncology during a long course of treatment. This complexity of care makes it very challenging to infer route of transmission of resistant organisms based on epidemiological investigation alone. Real-time performance of whole-genome sequencing analysis would be more useful in the investigation of these outbreaks involving patients requiring complex medical care.

Patient-10, - 16, - 17, and - 18 carried IMP-producing non-ST78 ECC isolates, which suggests these patients incidentally acquired the isolates unrelated to the 


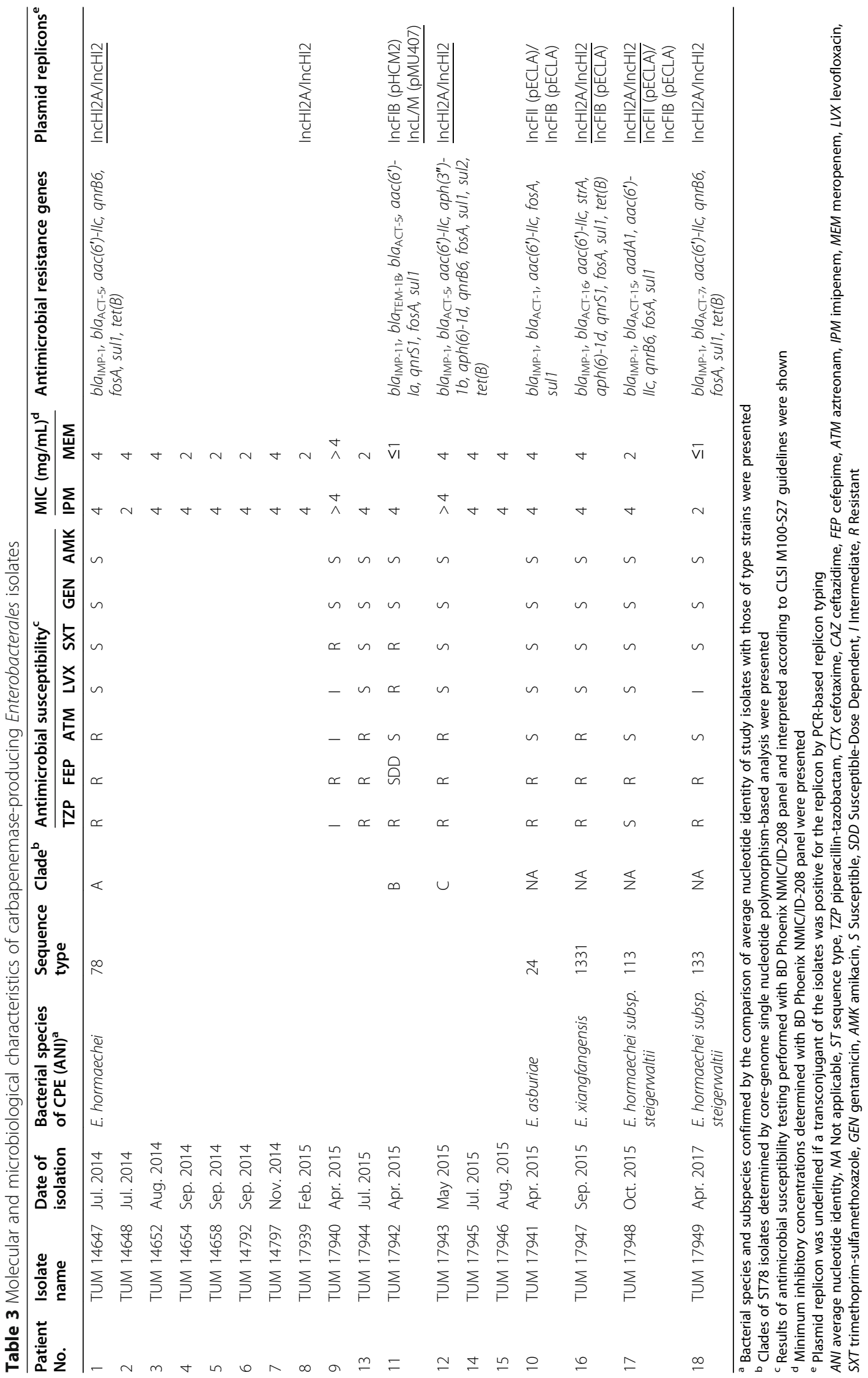


Clade A

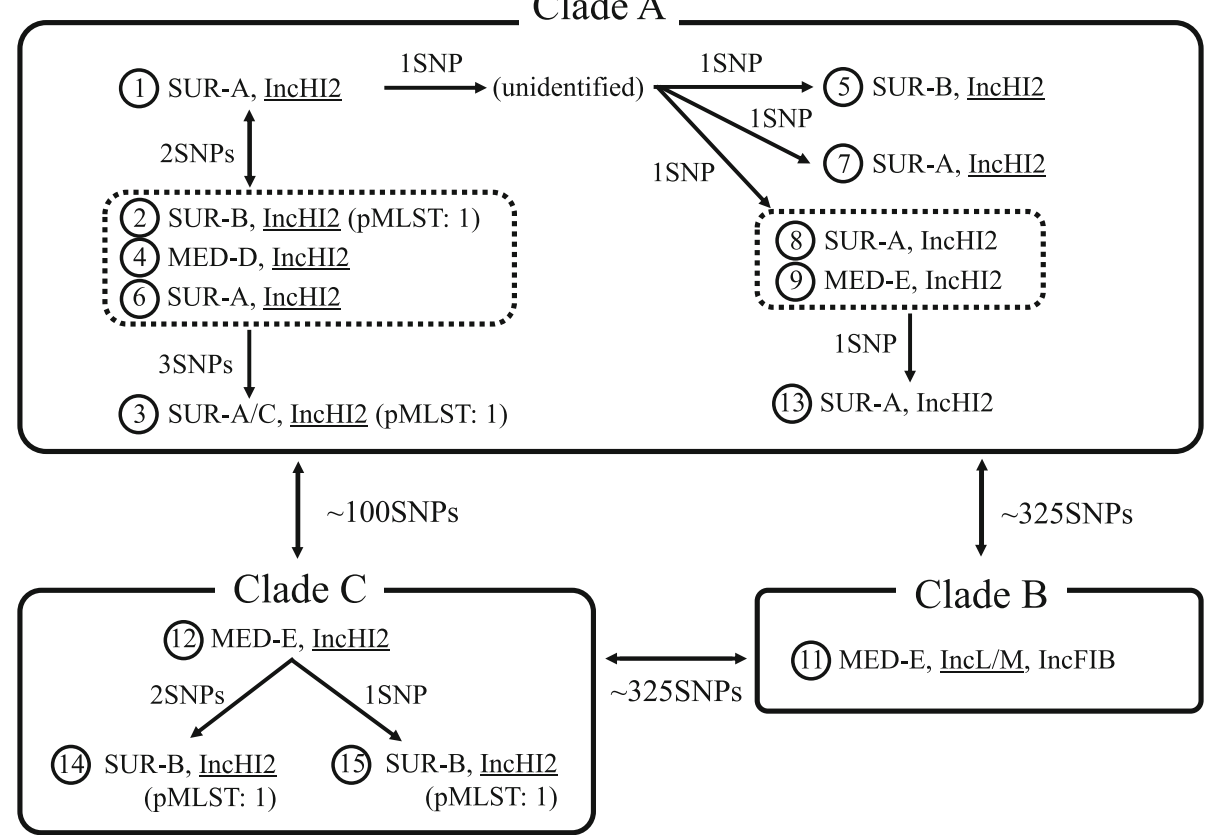

Fig. 2 Molecular relatedness of the ST78 isolates from the patients. Isolates were indicated as circles with the patient designation numbers. The departments caring the patients at the time of isolation of ST78 isolates and plasmid replicons of the isolates identified by whole-genome sequencing analysis were shown. Plasmid replicon was underlined if a transconjugant of the isolates carrying bla by PCR-based replicon typing. PMLST profiles were also shown for the isolates with confirmed results. SNP deference of the isolates from the patients were presented and isolates without SNP difference were enclosed in dotted lines. Isolates belonging to the same clade were enclosed in solid lines. SUR, Surgery; MED, Medical Oncology

outbreak. Notably, two non-ST78 isolates (TUM17947 and TUM17948) carried $b l a_{\mathrm{IMP}-1}$ on IncHI2 plasmids. Carriage of bla $a_{\mathrm{IMP}-1}$ on IncHI2 plasmids by ECC isolates of multiple STs (e.g., ST53, 78, 113, 513, 1047) has been documented in another area (Nagoya) in Japan [25]. Although ST78 isolates appears to predominate among IMP-producing ECC isolates in Tokyo according to our previous study, the nationwide epidemiology remains to be elucidated [6]. Although there is the possibility of conjugative transfer of IncHI2 plasmids carrying bla $_{\mathrm{IMP}-1}$ between ST78 isolates and non-ST78 isolates in the hospital environment or in the flora of the patients, it is beyond the scope of our analysis.

In this study, most of the IMP-producing ECC isolates were susceptible to non- $\beta$-lactam antibiotics and had relatively low MICs $(\leq 4 \mu \mathrm{g} / \mathrm{mL})$ to carbapenems. Furthermore, several isolates were susceptible to non-carbapenem $\beta$ lactams such as piperacillin-tazobactam and aztreonam. These patterns of antimicrobial susceptibilities were similar to the IMP-producing Enterobacterales in Japan in previous reports $[6,10]$. Infections caused by IMP-producing ECC were treated successfully mainly with non- $\beta$-lactam antibiotics retaining activity to the organisms except a case of intraabdominal infection without adequate source control (Table 2). Better prognosis of infections caused by MBL-producing Enterobacterales associated with better antimicrobial susceptibilities compared with those caused by KPC-producing Enterobacterales, which was consistent with our observation, was reported in an observational study [26].

Our study has several limitations. First, there could have been missed patients carrying CPE in the outbreak for several reasons. Active surveillance cultures were performed for a limited number of times for selected wards only. In addition, selective media for ESBL, not specific for CPE, was used for surveillance culture. Although previous studies showed that selective media for ESBL had $>90 \%$ sensitivity for the isolation of CPE as a whole, the ability to identify IMP-producing isolates was unclear [27]. Screening criteria for the routine culture testing for the performance of confirmation testing for carbapenemase production were not strict enough to identify all CPE isolates. However, the lack of isolation of IMP-producing ECC clonal isolates for more than 2 years after August 2015 suggests successful containment of major transmissions with reinforcement of compliance to infection prevention protocols including hand hygiene practice. Second, we have not identified the direct route of introduction and transmission of IMPproducing ECC isolates. Apparent common sources were not identified by clinical epidemiological analysis and surveillance cultures of medical devices such as 
endoscopes were negative. Third, number of the cases of infections caused by IMP-producing ECC was too limited to analyze the association between the treatment regimen and prognosis.

\section{Conclusions}

Involvement of multiple clades of ST78 isolates was documented by whole-genome sequencing analysis of IMPproducing ECC isolates identified in a hospital-wide outbreak. Genetic relatedness of the isolates unexpected by the clinical analysis was uncovered. Real-time performance of whole-genome sequencing of relevant bacterial isolates in complicated epidemiological situations could facilitate identification transmission route, which is vital in containing outbreaks of antimicrobial-resistant organisms.

\section{Abbreviations}

CRE: Carbapenem-resistant Enterobacterales; CPE: Carbapenemase-producing Enterobacterales; MBL: Metallo- $\beta$-lactamase; ECC: Enterobacter cloacae complex; SMA: Sodium mercaptoacetate; mCIM: Modified carbapenem inactivation method; ANI: Average nucleotide identity; MLST: Multilocus sequence typing; BLAST: Basic local alignment search tool; SNP: Single nucleotide polymorphism; ICU: Intensive care unit; ESBL: Extended-spectrum $\beta$-lactamases

\section{Supplementary Information}

The online version contains supplementary material available at https://doi. org/10.1186/s12879-021-05952-9.

Additional file 1: Table S1. Characteristics of each patient from whom carbapenemase-producing Enterobacterales strains were isolated.

\section{Acknowledgements}

None.

\section{Authors' contributions}

SH designed the study, contributed to the analysis and interpretation of data, and drafted the manuscript. KA contributed to the acquisition, analysis, and interpretation of data. DO, KT, TA, KI, and DS contributed to the acquisition of data. $\mathrm{KO}, \mathrm{Yl}, \mathrm{YD}$, and $\mathrm{KM}$ revised the manuscript critically for important intellectual content. BH provided administrative support of the research. All authors read and approved the final manuscript.

\section{Funding}

This research did not receive any specific grant from funding agencies in the public, commercial, or not-for-profit sectors.

\section{Availability of data and materials}

All data generated or analysed during this study are included in this published article.

\section{Declarations}

\section{Ethics approval and consent to participate}

Institutional review board approval was obtained prior to initiating the study (approval number: 2018-1013). All procedures performed in studies involving human participants were in accordance with the 1964 Helsinki declaration and its later amendments or comparable ethical standards. Specific informed consent for this retrospective and non-invasive study was not required by local ethics committee.

\section{Consent for publication}

Not applicable since there are no details on individuals reported within the manuscript.

\section{Competing interests}

SH reports personal fees from BD, Meiji, Shionogi, Sumitomo Dainippon Pharma, MSD, Astellas, Beckman Coulter Diagnostics, and FUJIFILM Toyama Chemical, and grants from MSD, outside the submitted work. YD reports personal fees from Pfizer, MSD, Shionogi, Janssen, VenatoRx, Entasis, BD, bioMerieux, Gilead, and AstraZeneca, and grants from Pfizer, MSD, Astellas, Shionogi, Kanto Chemical, and Janssen, outside the submitted work. All other authors declare no conflict of interest relevant to the study.

\section{Author details}

${ }^{1}$ Department of Infection Control and Prevention, The University of Tokyo Hospital, 7-3-1 Hongo, Bunkyo-ku, Tokyo 113-8655, Japan. ²Department of Infectious Diseases, Cancer Institute Hospital, Japanese Foundation for Cancer Research, 3-8-31 Ariake, Koto-ku, Tokyo 135-8550, Japan. ${ }^{3}$ Department of Microbiology and Infectious Diseases, Toho University School of Medicine, 5-21-16 Omori-nishi, Ota-ku, Tokyo 143-8540, Japan. ${ }^{4}$ Department of Infectious Diseases, The University of Tokyo Hospital, 7-3-1 Hongo, Bunkyo-ku, Tokyo 113-8655, Japan. ${ }^{5}$ Clinical Laboratory, Cancer Institute Hospital, Japanese Foundation for Cancer Research, 3-8-31 Ariake, Koto-ku, Tokyo 135-8550, Japan. ${ }^{6}$ Department of Infection Prevention, Cancer Institute Hospital, Japanese Foundation for Cancer Research, 3-8-31 Ariake, Koto-ku, Tokyo 135-8550, Japan. 7 Department of Pharmacy, Cancer Institute Hospital, Japanese Foundation for Cancer Research, 3-8-31 Ariake, Koto-ku, Tokyo 135-8550, Japan. ${ }^{8}$ Department of Infectious Diseases, Fujita Health University School of Medicine, 1-98 Dengakugakubo, Kutsukake-cho, Toyoake, Aichi 470-1192, Japan. ${ }^{9}$ Division of Infectious Diseases, University of Pittsburgh School of Medicine, 3550 Terrace Street, Pittsburgh, PA 15261, USA.

Received: 12 August 2020 Accepted: 3 March 2021

Published online: 22 March 2021

\section{References}

1. Koulenti D, Song A, Ellingboe A, Abdul-Aziz MH, Harris P, Gavey E, Lipman J. Infections by multidrug-resistant gram-negative Bacteria: What's new in our arsenal and what's in the pipeline? Int J Antimicrob Agents. 2019;53(3):21124. https://doi.org/10.1016/j.ijantimicag.2018.10.011.

2. Tamma PD, Goodman KE, Harris AD, Tekle T, Roberts A, Taiwo A, Simner PJ. Comparing the outcomes of patients with Carbapenemaseproducing and non-Carbapenemase-producing Carbapenem-resistant Enterobacteriaceae bacteremia. Clin Infect Dis. 2017;64(3):257-64. https://doi.org/10.1093/cid/ciw741.

3. Mathers AJ, Cox HL, Kitchel B, Bonatti H, Brassinga AK, Carroll J, Scheld WM, Hazen KC, Sifri CD. Molecular dissection of an outbreak of carbapenemresistant enterobacteriaceae reveals Intergenus KPC carbapenemase transmission through a promiscuous plasmid. mBio. 2011;2(6):e00204-11. https://doi.org/10.1128/mBio.00204-11.

4. Logan LK, Weinstein RA. The Epidemiology of Carbapenem-Resistant Enterobacteriaceae: The Impact and Evolution of a Global Menace. J Infect Dis. 2017;215(suppl_1):S28-36.

5. Yamamoto N, Asada R, Kawahara R, Hagiya H, Akeda Y, Shanmugakani RK, Yoshida H, Yukawa S, Yamamoto K, Takayama Y, Ohnishi H, Taniguchi T, Matsuoka T, Matsunami K, Nishi I, Kase T, Hamada S, Tomono K. Prevalence of, and risk factors for, carriage of carbapenem-resistant Enterobacteriaceae among hospitalized patients in Japan. J Hosp Infect. 2017;97(3):212-7. https://doi.org/10.1016/j.jhin.2017.07.015.

6. Aoki K, Harada S, Yahara K, Ishii Y, Motooka D, Nakamura S, Akeda Y, lida T, Tomono K, Iwata S, Moriya K, Tateda K. Molecular characterization of IMP-1producing Enterobacter cloacae Complex isolates in Tokyo. Antimicrob Agents Chemother. 2018;62(3):e02091-17.

7. Snitkin ES, Zelazny AM, Thomas PJ, Stock F, NISC Comparative Sequencing Program Group, Henderson DK, Palmore TN, Segre JA. Tracking a hospital outbreak of carbapenem-resistant Klebsiella pneumoniae with wholegenome sequencing. Sci Transl Med. 2012;4(148):148ra116.

8. Kanamori H, Parobek CM, Juliano JJ, van Duin D, Cairns BA, Weber DJ, Rutala WA. A prolonged outbreak of KPC-3-producing Enterobacter cloacae and Klebsiella pneumoniae driven by multiple mechanisms of resistance transmission at a large academic burn center. Antimicrob Agents Chemother. 2017;61(2):e01516.

9. Roberts LW, Harris PNA, Forde BM, Ben Zakour NL, Catchpoole E, StantonCook M, Phan MD, Sidjabat HE, Bergh H, Heney C, Gawthorne JA, Lipman J, Allworth A, Chan KG, Chong TM, Yin WF, Schembri MA, Paterson DL, 
Beatson SA. Integrating multiple genomic technologies to investigate an outbreak of carbapenemase-producing Enterobacter hormaechei. Nat Commun. 2020;11(1):466. https://doi.org/10.1038/s41467-019-14139-5.

10. Hayakawa K, Nakano R, Hase R, Shimatani M, Kato H, Hasumi J, Doi A Sekiya N, Nei T, Okinaka K, Kasahara K, Kurai H, Nagashima M, MiyoshiAkiyama T, Kakuta R, Yano H, Ohmagari N. Comparison between IMP carbapenemase-producing Enterobacteriaceae and non-carbapenemaseproducing Enterobacteriaceae: a multicentre prospective study of the clinical and molecular epidemiology of carbapenem-resistant Enterobacteriaceae. J Antimicrob Chemother. 2020;75(3):697-708. https:// doi.org/10.1093/jac/dkz501.

11. Gutiérrez-Gutiérrez B, Salamanca E, de Cueto M, Hsueh PR, Viale P, Paño-Pardo JR, Venditti M, Tumbarello M, Daikos $G$, Cantón R, Doi $Y$, Tuon FF, Karaiskos I, Pérez-Nadales E, Schwaber MJ, Azap ÖK, Souli M, Roilides E, Pournaras S, Akova M, Pérez F, Bermejo J, Oliver A, Almela M, Lowman W, Almirante B, Bonomo RA, Carmeli Y, Paterson DL, Pascual A, Rodríguez-Baño J, REIPI/ESGBIS/INCREMENT Investigators. Effect of appropriate combination therapy on mortality of patients with bloodstream infections due to carbapenemase-producing Enterobacteriaceae (INCREMENT): a retrospective cohort study. Lancet Infect Dis. 2017:17(7):726-34.

12. Horan TC, Andrus M, Dudeck MA. CDC/NHSN surveillance definition of health care-associated infection and criteria for specific types of infections in the acute care setting. Am J Infect Control. 2008;36(5):309-32. https://doi. org/10.1016/j.ajic.2008.03.002.

13. Clinical and Laboratory Standards Institute. Performance standards for antimicrobial susceptibility testing. Seventeenth informational supplement. Wayne: CLSI document M100-S17; 2007.

14. Clinical and Laboratory Standards Institute. Performance standards for antimicrobial susceptibility testing. Twenty-second informational supplement. Wayne: CLSI document M100-S22; 2012.

15. Yano H, Ogawa M, Endo S, Kakuta R, Kanamori H, Inomata S, Ishibashi N Aoyagi T, Hatta M, Gu Y, Yamada M, Tokuda K, Kunishima H, Kitagawa M, Hirakata Y, Kaku M. High frequency of IMP-6 among clinical isolates of metallo- $\beta$-lactamase-producing Escherichia coli in Japan. Antimicrob Agents Chemother. 2012;56(8):4554-5. https://doi.org/10.1128/AAC.00617-12.

16. Hattori T, Kawamura K, Arakawa Y. Comparison of test methods for detecting metallo- $\beta$-lactamase-producing gram-negative bacteria. Jpn J Infect Dis. 2013;66(6):512-8. https://doi.org/10.7883/yoken.66.512.

17. Arakawa Y, Shibata N, Shibayama K, Kurokawa H, Yagi T, Fujiwara H, Goto M. Convenient test for screening metallo-beta-lactamaseproducing gram-negative bacteria by using thiol compounds. J Clin Microbiol. 2000;38(1):40-3.

18. Clinical and Laboratory Standards Institute. Performance standards for antimicrobial susceptibility testing. 27th ed. Wayne: CLSI supplement M100; 2017.

19. Shibata N, Doi Y, Yamane K, Yagi T, Kurokawa H, Shibayama K, Kato H, Kai K, Arakawa Y. PCR typing of genetic determinants for metallo-beta-lactamases and integrases carried by gram-negative bacteria isolated in Japan, with focus on the class 3 integron. J Clin Microbiol. 2003;41(12):5407-13. https:// doi.org/10.1128/JCM.41.12.5407-5413.2003.

20. Chavda KD, Chen L, Fouts DE, Sutton G, Brinkac L, Jenkins SG, Bonomo RA, Adams MD, Kreiswirth BN. Comprehensive Genome Analysis of Carbapenemase-Producing Enterobacter spp.: New Insights into Phylogeny, Population Structure, and Resistance Mechanisms. mBio. 2016;7(6):e02093-16.

21. Carattoli A, Bertini A, Villa L, Falbo V, Hopkins KL, Threlfall EJ. Identification of plasmids by PCR-based replicon typing. J Microbiol Methods. 2005;63(3): 219-28. https://doi.org/10.1016/j.mimet.2005.03.018.

22. Izdebski R, Baraniak A, Herda M, Fiett J, Bonten MJ, Carmeli Y, Goossens H, Hryniewicz W, Brun-Buisson C, Gniadkowski M, MOSAR WP2, WP3 and WP5 Study Groups. MLST reveals potentially high-risk international clones of Enterobacter cloacae. J Antimicrob Chemother. 2015;70(1):48-56. https://doi. org/10.1093/jac/dku359.

23. Matsumura Y, Peirano G, Motyl MR, Adams MD, Chen L, Kreiswirth B, DeVinney R, Pitout JD. Global molecular epidemiology of IMP-producing Enterobacteriaceae. Antimicrob Agents Chemother. 2017;61(4):e02729-16.

24. Peirano G, Matsumura Y, Adams MD, Bradford P, Motyl M, Chen L, Kreiswirth BN, Pitout JDD. Genomic epidemiology of global Carbapenemaseproducing Enterobacter spp., 2008-2014. Emerg Infect Dis. 2018;24(6):10109. https://doi.org/10.3201/eid2406.171648.
25. Tetsuka N, Hirabayashi A, Matsumoto A, Oka K, Hara Y, Morioka H, Iguchi M, Tomita Y, Suzuki M, Shibayama K, Yagi T. Molecular epidemiological analysis and risk factors for acquisition of carbapenemase-producing Enterobacter cloacae complex in a Japanese university hospital. Antimicrob Resist Infect Control. 2019;8:126.

26. Wang X, Wang Q, Cao B, Sun S, Zhang Y, Gu B, Li B, Liao K, Zhao F, Jin L, Jin C, Yang C, Pei F, Zhang Z, Wang H. Retrospective observational study from a Chinese network of the impact of combination therapy versus Monotherapy on mortality from Carbapenem-resistant Enterobacteriaceae bacteremia. Antimicrob Agents Chemother. 2018;63(1):e01511-8.

27. Wilkinson KM, Winstanley TG, Lanyon C, Cummings SP, Raza MW, Perry JD. Comparison of four chromogenic culture media for carbapenemaseproducing Enterobacteriaceae. J Clin Microbiol. 2012;50(9):3102-4. https:// doi.org/10.1128/JCM.01613-12.

\section{Publisher's Note}

Springer Nature remains neutral with regard to jurisdictional claims in published maps and institutional affiliations.
Ready to submit your research? Choose BMC and benefit from:

- fast, convenient online submission

- thorough peer review by experienced researchers in your field

- rapid publication on acceptance

- support for research data, including large and complex data types

- gold Open Access which fosters wider collaboration and increased citations

- maximum visibility for your research: over $100 \mathrm{M}$ website views per year

At BMC, research is always in progress.

Learn more biomedcentral.com/submissions 